1968). Alternatively, it may represent the diurnal variation in fasting blood sugar levels in established diabetics shown by Faiman and Moorhouse (1967). These workers reported that during three-day fasts five diabetic subjects showed a diurnal cycle in their blood glucose levels, with the peak levels occurring around 8 a.m.; no such cycle could be discerned in five healthy controls.

The inverse relation of obesity, as measured by the ponderal index, with the degree of diurnal variation in glucose tolerance, was significant only in the normoglycaemic group, but was also evident in the hyperglycaemic group. Since the morning glucose tolerance area is itself associated directly with the degree of obesity, it is difficult to decide how much of the loss of diurnal variation to attribute to obesity per se and how much to the associated hyperglycaemia. The analyses of the control group in Tables II and III, however, suggest that obesity is the more potent factor when morning glycaemia is within the normal range and is perhaps an independent one.

Diagnostic classification of the tests yields many abnormalities by afternoon testing in the group preselected for normoglycaemia. By one system of classification (Table VIII) all the morning tests were normal, but 10 afternoon tests were abnormal. Table IX lists the paired tests in these 10 subjects, and in all but one (No. 2) the morning tests are unequivocally normal. In some, however, the diurnal swing is so greatfor example, Nos. 6, 7, and 9-as to bring the test results into what most would regard as the conventionally diabetic range. The present and potential significance of this phenomenon can only be hypothetical. This exaggerated swing may possibly represent an earler stage in the failure of glucose homoeostasis than the reduced swing seen in those with morning hyperglycaemia. Obviously, only longitudinal studies can provide the answer, and these are fraught with difficulties, not least logistical ones. A suggested working hypothesis, however, is that afternoon hyperglycaemia is the first stage of glucose intolerance, followed by increased morning glycaemia (and reduced diurnal variation), then proceeding to morning hyperglycaemia, sufficient eventually to warrant the description of diabetes mellitus.

The small diurnal difference in mean two-hour blood sugar levels measured under screening conditions agrees with our previous experience (Keen, 1966) and presumably accounts for the failure of others to find diurnal variation in population surveys (Hayner et al., 1965; Marine et al., 1969). The reason for the relative lack of diurnal variation under these conditions is probably related to the lesser degree of standardization obtaining. Though the mean blood sugar levels were similar, the variation was very much greater in the afternoon, so that afternoon screening would be likely to yield more subjects exceeding an arbitrary cut-off level.

We are grateful to the many men who volunteered to participate in this study, and to our colleagues at the London School of Hygiene for their co-operation. Our contribution to the main survey and follow-up is financed by a grant from the Department of Health and Social Security. R. J. J. wishes to thank Lilly Laboratories for additional financial support.

\section{REFERENCES}

Bowen, A. J., and Reeves, R. L. (1967). Archives of Internal Medicine, 119,

Faiman, C., and Moorhouse, J. A. (1967). Clinical Science, 32, 111.

Faiman, C., and Moorhouse, J. A. (1967). Clinical Science, 32, 111.
Faludi, G., Bendersky, G., and Gerber, P. (1968). Annals of the New York Academy of Sciences, 148, 868.

Fitzgerald, M. G., and Keen, H. (1964). British Medical fournal, 1, 1568.

Hayner, N. S., Kjelsberg, M. O., Epstein, F. H., and Francis, T., jun (1965). Diabetes, 14, 413.

Jarrett, R. J. (1970). Diabetologia. 6, 453.

Jarrett, R. J., and Keen, H. (1969). British Medical fournal, 2, 341

Keen, H. (1966). Proceedings of the Royal Society of Medicine, 59, 1169. Keen, H., and Jarrett, R. J. (1969). Proceedings of the 2nd International Symposium on Atherosclerosis. In press.

Marine, N., Vinik, A. I., Edelstein, I., and Jackson, W. P. U. (1969) Diabetes, 18, 840 .

Roberts, H. J. (1964). Fournal of the American Geriatrics Society, 12, 423

Seltzer, H. S., Fajans, S. S., and Conn, J. W. (1959). Diabetes, 5, 437.

Steinkamp, R. C., et al. (1965). Fournal of Chronic Diseases, 18, 1291.

\title{
Exercise Asthma and Disodium Cromoglycate
}

\author{
H. POPPIUS, ${ }^{*}$ M.D. ; A. MUITTARI, ${ }^{*}$ M.D. ; K.-E. KREUS, $†$ M.D. \\ O. KORHONEN, $\dagger$ M.D. ; A. VILJANEN, $\dagger$ M.D.
}

\begin{abstract}
Cummary: Exercise-induced asthma (defined as a fall in PEF of at least $25 \%$ of the pre-exercise value) was studied in adult patients with uncomplicated asthma. This was found to occur in 22 out of 52 patients. Preexercise inhalation of disodium cromoglycate reduced the mean fall in PEF after maximal exercise from $50 \%$ of the pre-exercise value to $23 \%$ (open assessment in 11 cases). After submaximal exercise for eight minutes the reduction was from $18 \%$ to $10 \%$ (double-blind crossover study in 28 cases). It is concluded that disodium cromoglycate partly inhibits the increase of airways resistance after exercise in asthmatic patients.
\end{abstract}

\section{Introduction}

In asthmatics heavy exercise over several minutes may be followed by an increase in airways resistance (Pearson, 1952; McNeill et al., 1966; Sly et al., 1967; Sly, 1970), which is inhibited by sympathomimetics but usually not by atropine or \footnotetext{
* Senior lecturer, Department of Pulmonary Diseases, University Central
Hospital, Helsinki, Finland.

† Registrar, University Central Hospital, Helsinki.
}

cortisone (Jones et al., 1962; McNeill et al., 1966; Sly et al., 1967). The mechanism of the reaction has not been explained, though several suggestions and hypotheses have been presented (Seaton et al., 1969; Ward et al., 1969; Kerr et al., 1970).

Inhalation of disodium cromoglycate may inhibit the bronchoconstriction after inhalation provocation tests in patients with extrinsic asthma (Altounyan, 1967; Pepys et al., 1968; Muittari, 1969). Disodium cromoglycate is thought to block the mechanism by which bronchoconstrictive substances are released from mast cells after antigen-antibody reaction (Cox, 1967) or to inhibit the effect of pharmacologically active amines on bronchial smooth muscle or both (Kerr et al., 1970). Uncontrolled studies (Davies, 1968, Muittari and Kreus, 1969; Palmer and Legge, 1969; Ward et al., 1969) suggest that disodium cromoglycate may inhibit exercise-induced asthma. To our knowledge, however, no double-blind trials have been reported.

The purpose of the present study is (1) to estimate the prevalence, severity, and repeatability of exercise-induced asthma in inpatients with uncomplicated asthma and (2) to evaluate the effect of disodium cromoglycate on exerciseinduced asthma by using a double-blind cross-over technique. 


\section{Patients and Methods}

Seventy-four adult inpatients with uncomplicated asthma (Ciba Foundation Symposium, 1959) were studied in a relatively stable period of their disease when infection was controlled and they were able to tolerate a work load of 250 $\mathrm{kp} . \mathrm{m} . / \mathrm{min}$. for six minutes followed by one of $500 \mathrm{kp} . \mathrm{m} . / \mathrm{min}$. for at least two minutes.

Two kinds of exercise test were applied. In the standard exercise test the patient pedalled a bicycle ergometer (ElemaSchönander, Sweden) in the supine position, and the load was increased by steps according to the schedule $250,500,750$, $1,000 \mathrm{kp} . \mathrm{m} . / \mathrm{min}$., each load being kept up for six minutes. The test was continued up to the subject's limit of exercise tolerance, estimated from either the actual test or a previous one. In the modified exercise test the subject was exposed to one and the same load, $400,500,600$, or $800 \mathrm{kp} . \mathrm{m}$. $/ \mathrm{min}$., for eight minutes. The load was chosen on the basis of the patient's performance in a previous standard exercise test to represent a near-maximal level of exercise.

The heart rate was determined from the ECG. Peak expiratory flow (PEF) was measured with Wright's peak flow meter immediately before the exercise test and at several points of time after it (series 1 and 3: 10, 15, 20, and 30 minutes; series 2: $5,10,15,30,45$, and 60 minutes after exercise, see below). PEF is defined as the mean of the two highest out of five consecutive readings. The maximal fall in PEF from the pre-exercise value was taken as a measure of the change of airways obstruction and is stated in absolute values $(\triangle \mathrm{PEF}, 1 . / \mathrm{min}$.) and as a percentage of pre-exercise values $(\triangle \mathrm{PEF} \%)$.

In part of the experiments (series 3 , see below) the patient inhaled one hour before the exercise test $20 \mathrm{mg}$. of disodium cromoglycate without isoprenaline (the content of one capsule of Intal) or placebo, according to a double-blind cross-over arrangement.

The exercise tests were performed between 1 and 3 p.m., and repeated at intervals of one to three days. Administration of bronchodilators was omitted for at least five hours before the test.

Three series of patients were studied. Series 1 comprised 52 unselected consecutive asthmatics aged 15-39 years admitted to the hospital and fulfilling the criteria stated above. Twenty-two were men and 30 were women, the mean age being 27. The duration of disease varied from 1 to 35 (mean 8.8) years. Two or more skin tests were positive in 43 patients. Twenty patients had received periodical and three continuous corticosteroid treatment. Series 2 comprised three men and eight women aged 18-51 (mean 33) years in whom a preliminary standard exercise test was followed by a decrease in PEF of at least $25 \%$. Series 3 comprised 28 patients (10 males and 18 females) aged $15-42$ (mean 26) years in whom a preliminary standard exercise test was followed by a decrease in PEF of at least $25 \%$. Seventeen patients are included in both series 1 and 3. Informed consent was obtained for these procedures from all the patients concerned.

\section{Results}

Prevalence of Exercise-induced Asthma.-In series 1, consisting of unselected cases with pre-exercise PEF values ranging from 230 to $598 \mathrm{l} . / \mathrm{min}$. (mean value $413 \mathrm{l} . / \mathrm{min}$.), a standard exercise test was followed by a decrease in PEF of at least $25 \%$ in 22 of 52 cases ( $42 \%$ ) (Fig. 1).

Time Course of Exercise-induced Asthma.-The change in PEF during the first hour after a standard exercise test (series 2) is shown in Fig. 2. The fall in PEF was most definite between 5 and 30 minutes after exercise. One minute after exercise the PEF was often slightly higher than the pre-exercise value.

Effect of Disodium Cromoglycate on Exercise-induced

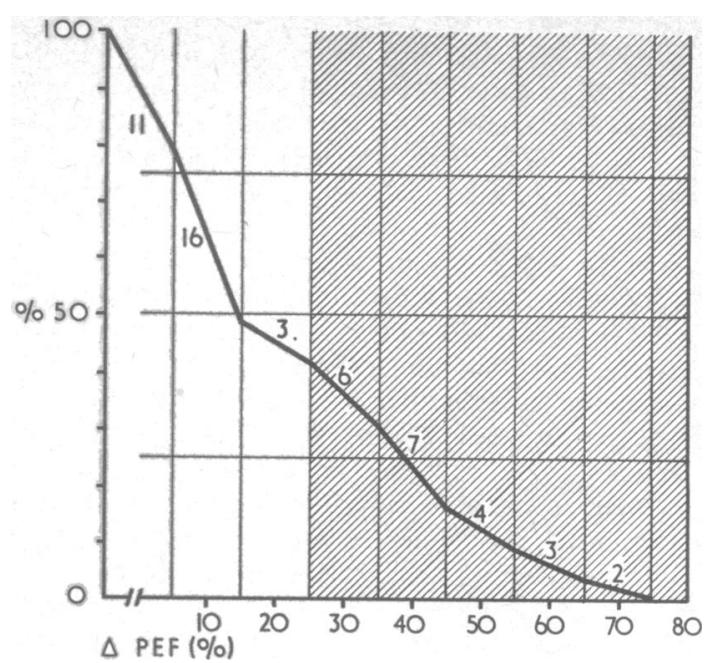

FIG. 1.-Cumulative percentages of 52 asthmatics showing different decrease of PEF following standard exercise test (series 1). A decrease of at least $25 \%$ of pre-exercise value was noted in $42 \%$ of cases.

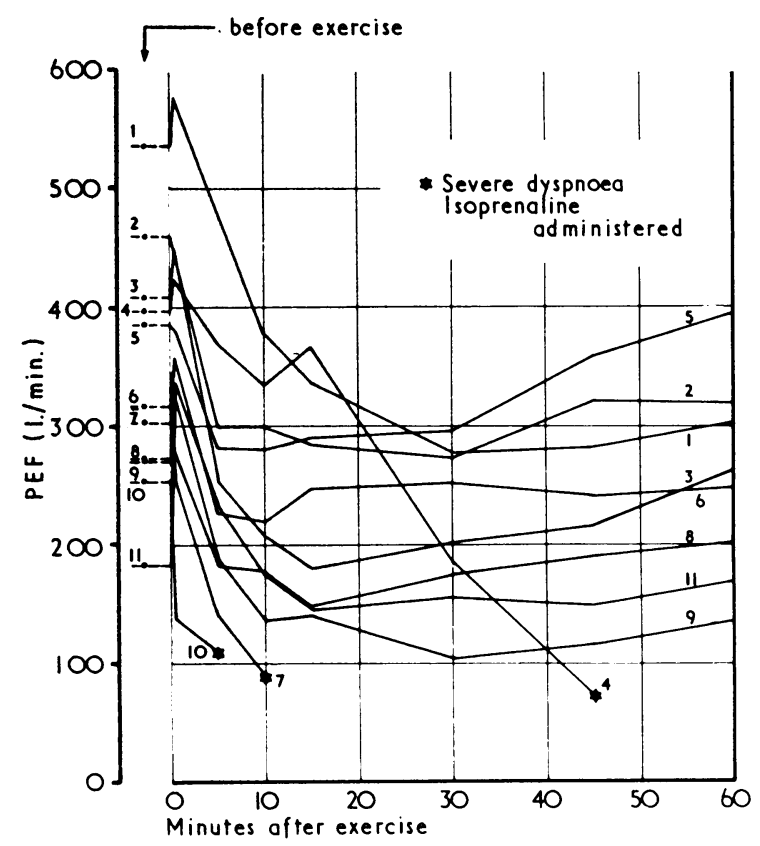

FIg. 2.-Time course of change in PEF after standard exercise test (series 2)

Asthma.-After a preliminary standard exercise test, patients in series 2 were subjected to three additional standard exercise tests (A, B, and C). One hour before Tests $A$ and $B$ the patients inhaled disodium cromoglycate. Test $C$ was done without premedication and served as control. Tests $A$ and $C$ were performed with the same work load and duration of exercise as in the preliminary test. In Test $B$ the patient was asked to exercise to the limit of his tolerance, the amount of exercise being somewhat greater than in A and C. The fall in PEF was $50 \%$ without premedication (C) and significantly less, $23 \%$ (A) or $31 \%$ (B), when disodium cromoglycate was given before exercise (Table I). After a preliminary standard exercise test, patients in series 3 were subjected to four identical modified submaximal exercise tests, two were preceded by inhalation of disodium cromoglycate and two by inhalation of placebo. The mean fall in PEF was $18 \%$ after placebo and significantly less $(10 \%)$ after disodium cromoglycate (Table II). The fall in PEF after severe exercise without premedication, in series 2 , was significantly greater $(P<0.001)$ than after submaximal exercise and placebo in series 3 . Series 2 
TABLE I.-Change in PEF after Heavy Exercise and Inhalation of Disodium Cromoglycate (DSCG) ( $A$ and B) or Without Medication (C). Exercise Load and Duration in $A$ and $C$ were Chosen to Correspond to the Patient's Maximum Exercise Tolerance in a Preliminary Exercise Test. In B, the Patient was Driven to his Actual Limit of Exercise Tolerance.

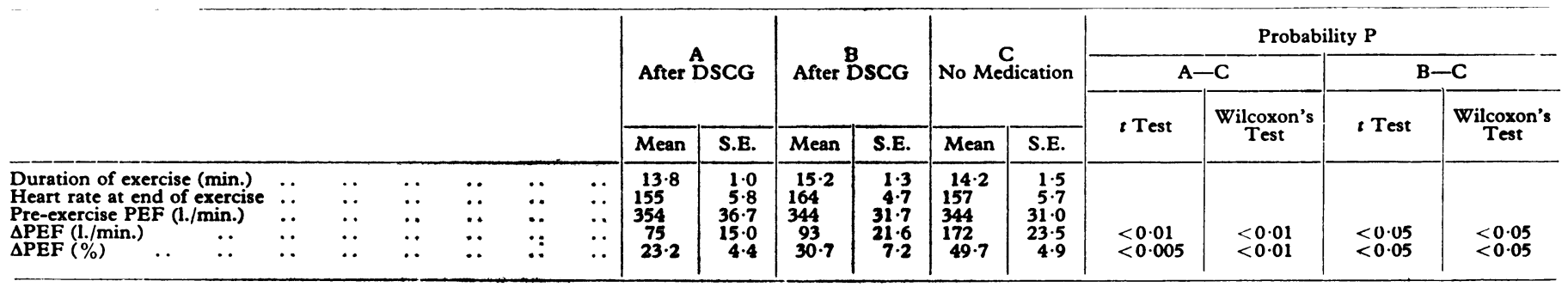

S.E. $=$ Standard Error

TABLE II.-Change in PEF Induced by Submaximal Exercise (400-800 kp.m./min.,' Mean Value 532 kp.m./min.) During Eight Minutes after kp.m.lmin., Mean Value 532 kp.m./min.) During Eight Minutes after
Inhalation of Disodium Cromoglycate (DSCG) or Placebo, Respectively, in 28 Patients with Exercise Asthma (Series 3). The Calculations are Based on Mean Values from Duplicate Tests

\begin{tabular}{|c|c|c|c|c|c|c|}
\hline & \multicolumn{2}{|c|}{$\begin{array}{c}\text { After } \\
\text { DSCG }\end{array}$} & \multicolumn{2}{|c|}{$\begin{array}{c}\text { After } \\
\text { Placebo }\end{array}$} & \multicolumn{2}{|c|}{ Probability P } \\
\hline & Mean & S.E. & Mean & S.E. & \& Test & $\begin{array}{c}\text { Wilcoson's } \\
\text { Test }\end{array}$ \\
\hline 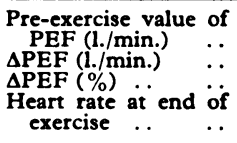 & $\begin{array}{c}392 \\
37 \\
10 \cdot 4 \\
144\end{array}$ & $\begin{array}{r}15 \cdot 8 \\
8 \cdot 2 \\
2 \cdot 3 \\
2 \cdot 5\end{array}$ & $\begin{array}{c}388 \\
65 \\
17 \cdot 8 \\
145\end{array}$ & $\begin{array}{r}15.6 \\
9.3 \\
2.6 \\
2.7\end{array}$ & $\begin{array}{l}<0.01 \\
<0.02\end{array}$ & $\begin{array}{l}<0.05 \\
<0.05\end{array}$ \\
\hline
\end{tabular}

TABLE III.-Repeatability of Pre-exercise PEF and Change in PEF after Submaximal Exercise During Eight Minutes after Inhalation of Placebo Submaximal Exercise During Eight Minutes after Inhalation of Placebo
or Disodium Cromoglycate (DSCG), Respectively, in 28 Patients with Exercise Asthma (Series 3). The Calculations are Based on Duplicate Tests

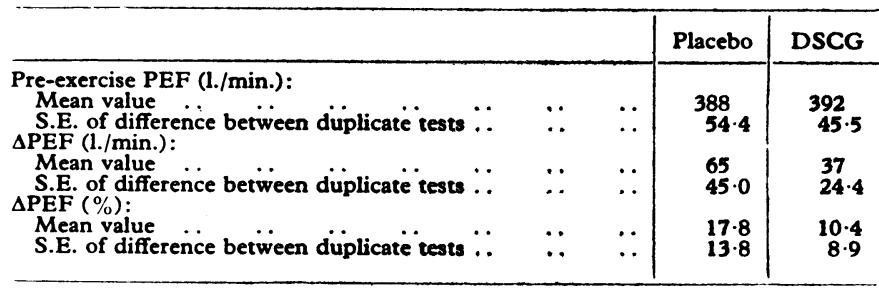

and 3 did not differ in the preliminary standard exercise test with regard to pre-exercise value of PEF (mean values \pm S.D.: $340 \pm 88 \mathrm{l} / \mathrm{min}$., and $379 \pm 87 \mathrm{l} . / \mathrm{min}$., respectively) or post-exercise fall in PEF (mean values \pm S.D. of $\triangle \mathrm{PEF} \%: 54 \pm 19$ and $47 \pm 13 \%$, respectively).

Repeatability of Exercise-induced Change in PEF.-The repeatability of change in PEF induced by the modified submaximal exercise test in series 3 is shown in Table III. The difference between duplicate tests after placebo with regard to post-exercise change in PEF was not found to be related to the differences of the pre-exercise PEF values $(r=0.299$, $\mathbf{P}>\mathbf{0 . 1}$ ).

\section{Discussion}

The prevalence of exercise-induced asthma in the present study $(42 \%$ in series 1$)$ is essentially higher than that reported by Irnell and Swartling (1966) in adult patients. Nevertheless, the latter studied their patients for only 10 minutes after exercise, while we observed them for 30 minutes. In our study the PEF often continued to fall after the first $\mathbf{1 0}$ minutes, and asthma attacks sometimes ensued as late as 30 to 45 minutes after exercise. In asthmatic children a significant decrease of PEF after exercise has been reported to occur in $25 \%$ by Kjellman (1969), in $47 \%$ by Sly (1970), and in $90 \%$ by Jones et al. (1962). The discrepancies between these findings may be explained by differences in respect of intensity, duration and type of exercise, criteria for significant change in ventilatory capacity, and selection of patients.

In the present study the repeatability of exercise-induced changes in PEF was assessed in 28 patients with known exercise asthma. With a standardized test procedure considerable variations in change of PEF after exercise were found in duplicate tests.

In keeping with the findings of Sly (1970), we did not find the percentile post-exercise change in PEF to be related to pre-exercise PEF level. On the other hand, heavy exercise in one group (series 2) up to the limit of subjective tolerance caused a fall in PEF almost three times as that induced by exercise at a submaximal level during eight minutes in a comparable group of patients (series 3 ). The exercise-induced change in airways resistance seems to be of considerable importance in considering the ability for physical work of patients with asthma.

In both the open-assessment series (2) and the double-blind series (3) disodium cromoglycate was found to reduce exerciseinduced asthma significantly. This may explain the finding that asthmatic patients can do their normal daily physical work when being treated with disodium cromoglycate.

\section{REFERENCES}

Altounyan, R. E. C. (1967). Acta Allergologica, 22, 487

Aitounyan, R. E. C. (1967). Acra Allergologica, 22, 487.

Cox, J. S. G. (1967). Nature, 216, 1328 .

Cox, J. S. G. (1967). Nature, 216, 1328. Irnell, S., and Swartling, S. (1966). Scandinavian fournal of Respiratory

Jones, R. S., Buston, M. H., and Wharton, M. J. (1962). British fournal of Diseases of the Chest, 56, 78.

Kerr, J. W., Govindaraj, M., and Patel, K. R. (1970). British Medica Sournal, 2, 139.

Kjellman, B. (1969). Scandinavian Fournal of Respiratory Diseases, 50, 41. McNeill, R. S., Nairn, J. R., Millar, J. S., and Ingram, C. G. (1966) Ouarterly fournal of Medicine, 35, 55 .

Muittari, A. (1969). Duodecim, 85, 1493.

Muittari, A., and Kreus, K.-E. (1969). British Medical fournal, 4, 170.

Palmer, K. N. V., and Legge, J. S. (1969). Lancet, 2, 219.

Pearson, R. S. B. (1952). Acta Allergologica, 5, 310.

Pepys, J., Hargreave, F. E., Chan, M., and McCarthy, D. S. (1968). Lancet, 2, 134.

Seaton, A., Davies, G., Gaziano, D., and Hughes, R. O. (1969). British

Medical Yournal, 3, 556.
Sly, R. M. (1970). Annals of Allergy, 28, 1.

Sly, R. M. (1970). Annals of Allergy, 28, 1.

Sly, R. M., Heimlich,

Ward, F. G., Gomes, S., and McNeill, R. S. (1969). British Medical fournal, $3,176$. 